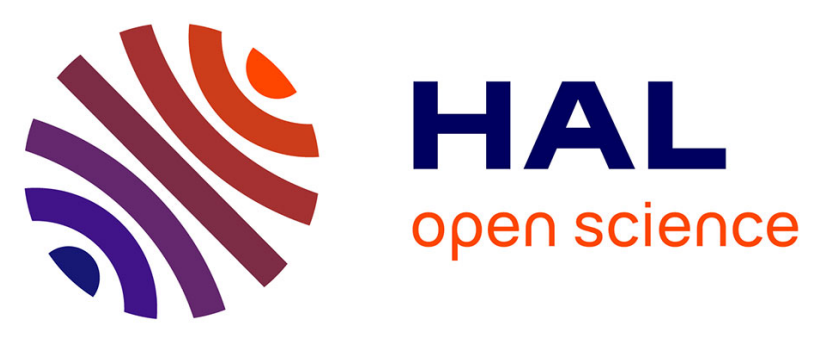

\title{
Exploring cardio-pulmonary interactions by examining the ventilatory, pulmonary gas exchange, and heart rate kinetics response to high-intensity cycle exercise in COPD patients
}

\author{
Bruno-Pierre Dubé, Pierantonio Laveneziana
}

\section{To cite this version:}

Bruno-Pierre Dubé, Pierantonio Laveneziana. Exploring cardio-pulmonary interactions by examining the ventilatory, pulmonary gas exchange, and heart rate kinetics response to high-intensity cycle exercise in COPD patients. Respiratory Physiology \& Neurobiology, 2015, 219, pp.103-105. 10.1016/j.resp.2015.09.010 . hal-01207785

\section{HAL Id: hal-01207785 \\ https://hal.sorbonne-universite.fr/hal-01207785}

Submitted on 1 Oct 2015

HAL is a multi-disciplinary open access archive for the deposit and dissemination of scientific research documents, whether they are published or not. The documents may come from teaching and research institutions in France or abroad, or from public or private research centers.
L'archive ouverte pluridisciplinaire HAL, est destinée au dépôt et à la diffusion de documents scientifiques de niveau recherche, publiés ou non, émanant des établissements d'enseignement et de recherche français ou étrangers, des laboratoires publics ou privés. 


\section{Exploring cardio-pulmonary interactions by examining the ventilatory, pulmonary gas exchange, and heart rate kinetics response to high-intensity cycle exercise in COPD patients}

\section{Authors:}

Bruno-Pierre Dubé ${ }^{1,2,3}$, Pierantonio Laveneziana ${ }^{1,4}$.

\section{Affiliations:}

${ }^{1}$ Sorbonne Universités, UPMC Université Paris 06, INSERM, UMRS_1158 Neurophysiologie respiratoire expérimentale et clinique, Paris, France.

${ }^{2}$ Assistance Publique-Hôpitaux de Paris (AP-HP), Groupe Hospitalier Pitié-Salpêtrière Charles Foix, Service de Pneumologie et Réanimation Médicale (Département "R3S", Pôle PRAGUES), Paris, France.

${ }^{3}$ Département de Médecine, service de Pneumologie, Hôpital Hôtel-Dieu du Centre Hospitalier de l'Université de Montréal (CHUM), Montréal, Canada.

${ }^{4}$ Assistance Publique-Hôpitaux de Paris (AP-HP), Groupe Hospitalier Pitié-Salpêtrière Charles Foix, Service des Explorations Fonctionnelles de la Respiration, de l'Exercice et de la Dyspnée (Département "R3S", Pôle PRAGUES), Paris, France.

Correspondence to: Dr. Pierantonio Laveneziana, Service d'Explorations Fonctionnelles de la Respiration, de l'Exercice et de la Dyspnée, Département "R3S" (Respiration, Réanimation, Réhabilitation, Sommeil), Pôle PRAGUES, Hôpital Universitaire Pitié-Salpêtrière, Assistance Publique-Hôpitaux de Paris (AP-HP), 47-83 Boulevard de l'Hôpital, 75013, Paris, France; Tel: $\begin{array}{llllllllllllllllll}00 & 33 & (0) & 1 & 42 & 17 & 85 & 84 & \text {; } & \text { Fax: } & 00 & 33 & \text { (0) } & 1 & 42 & 17 & 85 & 76\end{array}$ pierantonio.laveneziana@psl.aphp.fr

\section{Word count $=1782$}


In this Commentary, we aim to discuss a paper by Nasis et al. recently published in this journal (Nasis et al., 2015). As a basis for our comment, we would like to begin with a presentation of some background information of the topic of the relationship between cardiac and pulmonary variables during exercise. Cardio-pulmonary interactions can be difficult to explore in healthy and in COPD patients, especially during exercise. One method allowing access to these interactions is the examination of the ventilatory, pulmonary gas exchange, and heart rate kinetics response to high-intensity exercise. This is based on the assumption that the transition from rest to exercise can be characterized as having three phases (Whipp and Ward, 1982): 1) Phase I represents the cardiodynamic phase and reflects the abrupt increase in cardiac output, though rapid changes in mixed venous oxygen $\left(\mathrm{O}_{2}\right)$ and carbon dioxide $\left(\mathrm{CO}_{2}\right)$ content after the onset of loaded exercise have also been demonstrated (Casaburi et al., 1989); 2) Phase II represents the ability of the exercising muscles to utilize $\mathrm{O}_{2}$ from tissue stores and $\mathrm{O}_{2}$ transported by the circulation, and can be described by time constant $(\tau)$ analysis (Barstow et al., 1990; Chiappa et al., 2008). Thus, $\tau$ represents the time to reach $\approx 63 \%$ of the steady-state response of the parameters under consideration; 3) Phase III reflects the attainment of a steady-state value which can be either delayed or driven to maximum level, under high-intensity exercise condition, because of the appearance of slow component (Barstow et al., 1990).

Ventilatory and pulmonary gas exchange kinetics responses in COPD are abnormal and include: 1) reduced cardiodynamic phase, 2) sluggish Phase II, and 3) appearance of a slow component for oxygen uptake $\left(\mathrm{VO}_{2}\right)$ under high-intensity exercise condition. The existence of abnormal ventilatory, pulmonary gas exchange and heart rate kinetics has potentially negative implications for exercise performance in COPD patients (Chiappa et al., 2008; Laveneziana et al., 2009; Laveneziana et al., 2011; Puente-Maestu et al., 2000).

The precise mechanisms of sluggish ventilatory, pulmonary gas exchange and heart rate kinetics in cardio-pulmonary disease are not fully understood. Possible explanations include inadequacy of $\mathrm{O}_{2}$ delivery during the rest-to-exercise transition and derangements in the intracellular biochemical reactions that stimulate mitochondrial $\mathrm{O}_{2}$ uptake (i.e., “metabolic inertia') (Casaburi et al., 1989; Chiappa et al., 2008; DeLorey et al., 2005; Nery et al., 1982; Whipp and Wasserman, 1972). Additionally, in COPD, the increased work/oxygen cost of breathing and the preferential recruitment of type IIb fibres in the exercising peripheral skeletal muscles are believed to be important factors in determining the slow component (Aaron et al., 1992; Gaesser and Poole, 1996; Whipp, 1994). 
Therapeutic interventions, such as exercise training and normoxic heliox administration (21\% $\mathrm{O} 2$ and $79 \%$ Helium) have been shown to speed up ventilatory, pulmonary gas exchange, and heart rate kinetics in patients with COPD (Casaburi et al., 1997; Chiappa et al., 2009; Laveneziana et al., 2009; Laveneziana et al., 2011). Possible mechanisms include 1) an accelerated delivery of desaturated mixed venous blood to the central circulation, as a result of improved stroke volume responses to exercise, 2) improvements in intramuscular $\mathrm{O}_{2}$ utilisation (Casaburi et al., 1997; Chiappa et al., 2009), and 3) at least for normoxic heliox administration, a greater reliance on parasympathetic tone withdrawal for the increase in heart rate after the onset of exercise (Heindl et al., 2001). Briefly, the increase in heart rate through sympathetic activation is slower than that accomplished by parasympathetic withdrawal (Warner and Cox, 1962); the shift toward greater sympathetic activity with COPD (Heindl et al., 2001) would promote slowing of heart rate kinetics and, consequently, slowing of stroke volume adjustments to exercise. Thus, the well-known effects of normoxic heliox breathing on airways resistance (Eves et al., 2006), pulmonary arterial pressure (Lee et al., 2005) operating lung volumes (Chiappa et al., 2009; Eves et al., 2006; Laveneziana et al., 2009; Laveneziana et al., 2011; Palange et al., 2004), afferent signal coming from the large bronchi (that could be inhibited by normoxic heliox breathing) (Undem and Kollarik, 2005), and slow breathing during exercise (Raupach et al., 2008) may reduce sympathetic activity with consequent faster and larger parasympathetic withdrawal at the onset of loaded exercise.

It has recently been suggested that slower ventilatory, pulmonary gas exchange and heart rate kinetics in COPD may, in part, be the consequence of abnormal respiratory mechanics (Chiappa et al., 2008; Laveneziana et al., 2009; Laveneziana et al., 2011). The development of high mean intrathoracic pressures due to increased resistive and elastic loading of the respiratory muscles as ventilation (VE) abruptly increases in early exercise could dynamically impair the rate of right ventricle filling and left ventricle emptying. This, in turn, could lead to a reduction in peripheral muscle $\mathrm{O}_{2}$ delivery to a degree that is sufficient to impair ventilatory, pulmonary gas exchange, and heart rate kinetics (Chiappa et al., 2008; Laveneziana et al., 2009; Laveneziana et al., 2011). Moreover, there is emerging evidence that acute-on-chronic dynamic lung hyperinflation may deleteriously affect cardiac performance and disrupt the normal cardio-pulmonary interactions during exercise in COPD (Laveneziana et al., 2009; Laveneziana et al., 2011; Montes de Oca et al., 1996; Saito et al., 1999; Travers et al., 2007; Vassaux et al., 2008).

However, the extent to which these cardiovascular constraints imposed by dynamic lung hyperinflation influence ventilatory, pulmonary gas exchange and heart rate kinetics is 
not straightforward. It has recently been demonstrated that dynamic lung hyperinflation impairs cardiodynamic responses and convective $\mathrm{O}_{2}$ delivery during exercise in COPD, resulting in measurable delays in ventilatory, pulmonary gas exchange and heart rate kinetics compared with normal, and that 2) partial reversal of dynamic lung hyperinflation by acutely administered high-dose inhaled bronchodilator therapy was capable of speeding up ventilatory, pulmonary gas exchange, and heart rate kinetics in the transition from rest to high-intensity constant-work rate cycle exercise (Laveneziana et al., 2009; Laveneziana et al., 2011). Thus, unloading of the respiratory muscles, by reducing dynamic lung hyperinflation, may allow tidal breathing to occur on the more favourable linear portion of the respiratory pressure-volume curve, thus reducing intrathoracic pleural pressure swings as VE increases (Eves et al., 2006). This, in turn, may have positive effects on left ventricle afterload due to lower transmural pressures (Buda et al., 1979) and might improve cardiodynamic responses in the transition from rest to exercise (i.e., faster ventilatory, pulmonary gas exchange, and heart rate kinetics) resulting in improved convective oxygen delivery during exercise in COPD.

In their recently published paper, Nasis et al. (2015) used the cardio-bio-impedance technique to measure cardiac output and heart rate kinetics response at the onset and offset of high-intensity constant-work rate cycle exercise in COPD, before and after an interval cycling exercise training regime, in order to assess the relationship between exercise-induced dynamic lung hyperinflation and the abnormal hemodynamic response to exercise. Thus, for the first time in moderate-to-severe COPD, concomitant changes in dynamic lung hyperinflation, measured using inspiratory capacity during exercise, and central haemodynamics were determined. The authors found that the post-rehabilitation improvements in central haemodynamics were correlated with improvements in inspiratory capacity; thereby suggesting that mitigation of the degree of exercise-induced dynamic lung hyperinflation may contribute to improve central hemodynamic responses in COPD patients.

The training program used in the study was effective and induced expected physiological changes in patients, as witnessed by the improvements in maximal workrate, maximal VE, VE at iso-work, ventilatory threshold, maximal cardiac output during incremental exercise test and peak VE during constant-load exercise test. Patients with dynamic lung hyperinflation showed a mean improvement of $190 \mathrm{ml}$ in the amplitude of dynamic lung hyperinflation following training, which is in line with other studies (Porszasz et al., 2005; Puente-Maestu et al., 2003). Compared to COPD patients with stable inspiratory capacity during exercise, the finding that patients with dynamic lung hyperinflation had higher baseline (i.e. before intervention) mean response time (MRT, i.e., $\tau+$ time delay) for 
heart rate, stroke volume and cardiac output at the onset and recovery of the constant-load exercise test while having similar levels of baseline airflow obstruction further highlights the importance of lung hyperinflation (and, presumably, respiratory mechanics) as a determinant of the haemodynamic kinetics during exercise.

The improvement in MRT of the cardiac output following pulmonary rehabilitation was driven by an increase in the MRT of heart rate, rather than stroke volume. This is an interesting finding, as a decrease in magnitude of dynamic lung hyperinflation may have been expected, in light of the known effects of negative intrathoracic pressures on ejection fraction (Buda et al., 1979) to provide an improvement in left ventricular transmural pressures, afterload and the kinetics of stroke volume during exertion. The results from this study raise the question of whether the effects of an intervention such as a training program may predominantly provide its cardiocirculatory benefits from the improvement of sympatho-vagal balance, which could translate into a more favourable MRT of heart rate. As knowledge on the relationship between respiratory mechanical abnormalities and the autonomic system balance in COPD patients during exercise remains fragmentary (van Gestel et al., 2012; van Gestel and Steier, 2010), this hypothesis requires further study.

Strengths of the study by Nasis et al. include their use of well-defined COPD groups which mainly differed only by the presence of resting and dynamic lung hyperinflation, making easier the identification of the contribution of this variable to changes in cardio-pulmonary efficiency after training. In addition, although haemodynamic variables were determined noninvasively, the use of the Physio Flow impedance cardiograph device has been favourably compared with the Fick method in patients with COPD. Importantly, the precision of the device seems unaffected by the level of lung hyperinflation (Charloux et al., 2000).

A weakness/limitation of the present study however, from a physiological point of view, is the lack of oesophageal pressure-derived measurements of respiratory mechanics to infer a "real" benefit of rehabilitation on the respiratory mechanical abnormalities that characterise COPD, and the direct quantification of the correlation between such beneficial improvements and haemodynamics variables. The addition of such a measurement could have allowed to further corroborate the relationship between ventilatory and circulatory kinetics during exercise, but would arguably required more invasive manipulations. In addition, the use of a symptomlimited (instead of a fixed-time constant-load exercise test) could have provided further information on the interplay between changes in dynamic lung hyperinflation, haemodynamic 
kinetics and dyspnea, which, in the current form of the study, remained relatively low after the test.

Despite these limitations, especially the lack of oesophageal pressure-derived measurements of respiratory mechanics, we believe this study significantly adds to the field by highlighting the differences in physiological improvements following exercise training in different COPD populations and provides new insight regarding the relationship between the cardiocirculatory and ventilatory limitation during exercise in patients with COPD. 


\section{References}

Aaron, E.A., Seow, K.C., Johnson, B.D., Dempsey, J.A., 1992. Oxygen cost of exercise hyperpnea: implications for performance. Journal of applied physiology (Bethesda, Md. : 1985) 72, 1818-1825.

Barstow, T.J., Lamarra, N., Whipp, B.J., 1990. Modulation of muscle and pulmonary O2 uptakes by circulatory dynamics during exercise. Journal of applied physiology (Bethesda, Md. : 1985) 68, 979-989.

Buda, A.J., Pinsky, M.R., Ingels, N.B., Jr., Daughters, G.T., 2nd, Stinson, E.B., Alderman, E.L., 1979. Effect of intrathoracic pressure on left ventricular performance. N. Engl. J. Med. 301, 453-459.

Casaburi, R., Daly, J., Hansen, J.E., Effros, R.M., 1989. Abrupt changes in mixed venous blood gas composition after the onset of exercise. Journal of applied physiology (Bethesda, Md. : 1985) 67, 1106-1112.

Casaburi, R., Porszasz, J., Burns, M.R., Carithers, E.R., Chang, R.S., Cooper, C.B., 1997. Physiologic benefits of exercise training in rehabilitation of patients with severe chronic obstructive pulmonary disease. Am. J. Respir. Crit. Care Med. 155, 1541-1551.

Charloux, A., Lonsdorfer-Wolf, E., Richard, R., Lampert, E., Oswald-Mammosser, M., Mettauer, B., Geny, B., Lonsdorfer, J., 2000. A new impedance cardiograph device for the non-invasive evaluation of cardiac output at rest and during exercise: comparison with the "direct" Fick method. Eur. J. Appl. Physiol. 82, 313-320.

Chiappa, G.R., Borghi-Silva, A., Ferreira, L.F., Carrascosa, C., Oliveira, C.C., Maia, J., Gimenes, A.C., Queiroga, F., Jr., Berton, D., Ferreira, E.M., Nery, L.E., Neder, J.A., 2008. Kinetics of muscle deoxygenation are accelerated at the onset of heavy-intensity exercise in patients with COPD: relationship to central cardiovascular dynamics. Journal of applied physiology (Bethesda, Md. : 1985) 104, 1341-1350. 
Chiappa, G.R., Queiroga, F., Jr., Meda, E., Ferreira, L.F., Diefenthaeler, F., Nunes, M., Vaz, M.A., Machado, M.C., Nery, L.E., Neder, J.A., 2009. Heliox improves oxygen delivery and utilization during dynamic exercise in patients with chronic obstructive pulmonary disease. Am. J. Respir. Crit. Care Med. 179, 1004-1010.

DeLorey, D.S., Kowalchuk, J.M., Paterson, D.H., 2005. Adaptation of pulmonary O2 uptake kinetics and muscle deoxygenation at the onset of heavy-intensity exercise in young and older adults. Journal of applied physiology (Bethesda, Md. : 1985) 98, 1697-1704.

Eves, N.D., Petersen, S.R., Haykowsky, M.J., Wong, E.Y., Jones, R.L., 2006. Heliumhyperoxia, exercise, and respiratory mechanics in chronic obstructive pulmonary disease. Am. J. Respir. Crit. Care Med. 174, 763-771.

Gaesser, G.A., Poole, D.C., 1996. The slow component of oxygen uptake kinetics in humans. Exerc. Sport Sci. Rev. 24, 35-71.

Heindl, S., Lehnert, M., Criee, C.P., Hasenfuss, G., Andreas, S., 2001. Marked sympathetic activation in patients with chronic respiratory failure. Am. J. Respir. Crit. Care Med. 164, 597-601.

Laveneziana, P., Palange, P., Ora, J., Martolini, D., O'Donnell, D.E., 2009. Bronchodilator effect on ventilatory, pulmonary gas exchange, and heart rate kinetics during high-intensity exercise in COPD. Eur. J. Appl. Physiol. 107, 633-643.

Laveneziana, P., Valli, G., Onorati, P., Paoletti, P., Ferrazza, A.M., Palange, P., 2011. Effect of heliox on heart rate kinetics and dynamic hyperinflation during high-intensity exercise in COPD. Eur. J. Appl. Physiol. 111, 225-234.

Lee, D.L., Lee, H., Chang, H.W., Chang, A.Y., Lin, S.L., Huang, Y.C., 2005. Heliox improves hemodynamics in mechanically ventilated patients with chronic obstructive pulmonary disease with systolic pressure variations. Crit. Care Med. 33, 968-973. 
Montes de Oca, M., Rassulo, J., Celli, B.R., 1996. Respiratory muscle and cardiopulmonary function during exercise in very severe COPD. Am. J. Respir. Crit. Care Med. 154, 12841289.

Nasis, I., Kortianou, E., Vasilopoulou, M., Spetsioti, S., Louvaris, Z., Kaltsakas, G., Davos, C.H., Zakynthinos, S., Koulouris, N.G., Vogiatzis, I., 2015. Hemodynamic effects of high intensity interval training in COPD patients exhibiting exercise-induced dynamic hyperinflation. Respir. Physiol. Neurobiol. 217, 8-16.

Nery, L.E., Wasserman, K., Huntsman, D.J., Andrews, J.D., Hansen, J.E., Whipp, J., 1982. Ventilatory and gas exchange during exercise in chronic airway obstruction. J. Appl. Physiol. $53,1594-1602$.

Palange, P., Valli, G., Onorati, P., Antonucci, R., Paoletti, P., Rosato, A., Manfredi, F., Serra, P., 2004. Effect of heliox on lung dynamic hyperinflation, dyspnea, and exercise endurance capacity in COPD patients. Journal of applied physiology (Bethesda, Md. : 1985) 97, 16371642.

Porszasz, J., Emtner, M., Goto, S., Somfay, A., Whipp, B.J., Casaburi, R., 2005. Exercise training decreases ventilatory requirements and exercise-induced hyperinflation at submaximal intensities in patients with COPD. Chest 128, 2025-2034.

Puente-Maestu, L., Sanz, M.L., Sanz, P., Ruiz de Ona, J.M., Rodriguez-Hermosa, J.L., Whipp, B.J., 2000. Effects of two types of training on pulmonary and cardiac responses to moderate exercise in patients with COPD. Eur. Respir. J. 15, 1026-1032.

Puente-Maestu, L., Tena, T., Trascasa, C., 2003. Training improves muscle oxidative capacity and oxygenation recovery kinetics in patients with chronic obstructive pulmonary disease. Eur. J. Appl. Physiol. 88, 580-587. 
Raupach, T., Bahr, F., Herrmann, P., Luethje, L., Heusser, K., Hasenfuss, G., Bernardi, L., Andreas, S., 2008. Slow breathing reduces sympathoexcitation in COPD. Eur. Respir. J. 32, 387-392.

Saito, S., Miyamoto, K., Nishimura, M., Aida, A., Saito, H., Tsujino, I., Kawakami, Y., 1999. Effects of inhaled bronchodilators on pulmonary hemodynamics at rest and during exercise in patients with COPD. Chest 115, 376-382.

Travers, J., Laveneziana, P., Webb, K.A., Kesten, S., O'Donnell, D.E., 2007. Effect of tiotropium bromide on the cardiovascular response to exercise in COPD. Respir. Med. 101, 2017-2024.

Undem, B.J., Kollarik, M., 2005. The role of vagal afferent nerves in chronic obstructive pulmonary disease. Proceedings of the American Thoracic Society 2, 355-360; discussion 371-352.

van Gestel, A.J., Kohler, M., Clarenbach, C.F., 2012. Sympathetic overactivity and cardiovascular disease in patients with chronic obstructive pulmonary disease (COPD). Discov. Med. 14, 359-368.

van Gestel, A.J., Steier, J., 2010. Autonomic dysfunction in patients with chronic obstructive pulmonary disease (COPD). J. Thorac. Dis. 2, 215-222.

Vassaux, C., Torre-Bouscoulet, L., Zeineldine, S., Cortopassi, F., Paz-Diaz, H., Celli, B.R., Pinto-Plata, V.M., 2008. Effects of hyperinflation on the oxygen pulse as a marker of cardiac performance in COPD. Eur. Respir. J. 32, 1275-1282.

Warner, H.R., Cox, A., 1962. A mathematical model of heart rate control by sympathetic and vagus efferent information. J. Appl. Physiol. 17, 349-355.

Whipp, B.J., 1994. The slow component of O2 uptake kinetics during heavy exercise. Med. Sci. Sports Exerc. 26, 1319-1326. 


\section{Commentary relating to RESPNB3076.R2}

Whipp, B.J., Ward, S.A., 1982. Cardiopulmonary coupling during exercise. J. Exp. Biol. 100, $175-193$.

Whipp, B.J., Wasserman, K., 1972. Oxygen uptake kinetics for various intensities of constantload work. J. Appl. Physiol. 33, 351-356. 